\title{
Validation of an HPLC-UV Method for the Determination of Amiodarone Impurities in Tablet Formulations
}

\section{Fuad Al-Rimawi}

Faculty of Science and Technology, Al-Quds University, P.O. Box 20002, East Jerusalem

\begin{abstract}
A simple, precise, accurate, and stability-indicating liquid chromatographic method was validated for the determination of amiodarone hydrochloride impurities (amiodarone impurity $D$ and impurity $E$ ) as well as for the determination of amiodarone hydrochloride in tablet formulations. Liquid chromatography with a UV detector at a wavelength of $240 \mathrm{~nm}$ using a C18 column was employed in this study. Isocratic elution was employed using a mixture of buffer solution pH 5.0, methanol, and acetonitrile $(30: 30: 40, \mathrm{v} / \mathrm{v} / \mathrm{v})$. This method was validated for the determination of amiodarone hydrochloride in accordance with USP requirements for assay determination, which include accuracy, precision, selectivity, linearity and range. The current method demonstrates good linearity over the range of 0.005-0.015 $\mathrm{mg} \mathrm{mL}^{-1}$ of amiodarone hydrochloride. The \% recovery of the method is $99.7 \%$. The precision of this method reflected by relative standard deviation of sample replicates is $0.80 \%$. Validation of the same method for the determination of amiodarone impurity $\mathrm{D}$ and impurity $\mathrm{E}$ was also performed according to USP requirements for quantitative determination of impurities which include accuracy, precision, linearity and range, selectivity, and Limit of quantitation (LOQ). Low LOQ of amiodarone impurities using this method enables the detection and quantitation of these impurities at low concentration.
\end{abstract}

Keywords: Amiodarone hydrochloride; Amiodarone impurity D; Amiodarone impurity E; Validation

\section{Introduction}

Amiodarone is an antiarrhythmic agent used for irregular heart beat and for various types of tachyarrhythmias (fast forms of irregular heart beat). Amiodarone hydrochloride is formulated as tablet dosage forms and injectable formulations. There are many impurities of amiodarone, impurities $\mathrm{D}$ and $\mathrm{E}$ are well characterizes and identified impurities. The structures of impurity D and impurity E are similar, and therefore a stability-indicating method for the separation of these two impurities from each other and from amiodarone hydrochloride is needed. Structures of amiodarone hydrochloride and amiodarone impurities are shown in Figure 1.

Many HPLC methods were developed for the determination of amiodarone and its impurities. Lacroix et al. [1] has developed in 1994 an LC-method for determination of amiodarone hydrochloride<smiles>CCCc1oc2ccccc2c1C(=O)c1cc(I)c(OCCN(CC)CC)c(I)c1</smiles>

Amiodarone hydrochloride<smiles>[R2]c1cc(C(=O)c2c(CCCC)oc3ccccc23)cc([R])c1O</smiles>

Amiodarone impourity $\mathrm{D}$ and $\mathrm{E}$ (for impurity $\mathrm{D}$ : $\mathrm{R} 1=\mathrm{R} 2=\mathrm{I}$, for impurity E: R1 $=\mathrm{R} 2=\mathrm{H}$ )

Figure 1: Chemical structure of amiodarone hydrochloride and amiodarone impurities D and $E$. and its related compounds in raw materials and tablets [1]. Thyagarajapuram et al. [2] has developed an LC-method for the determination of amiodarone hydrochloride in tablet and injectable formulations [2]. An HPLC method was also developed and validated for the determination of amiodarone hydrochloride and its related compounds in amiodarone hydrochloride injections by Christopherson et al. [3]. In 2005, an HPLC method was developed and validated for the determination of amiodarone hydrochloride and its related substances [4]. All of theses methods, however, are validated only for the determination of amiodarone hydrochloride but not for the determination of amiodarone impurities. The objective of the current work is, therefore, to validate a stability-indicating HPLC method for the determination of amiodarone impurities (D and $E$ ) as well as for amiodarone hydrochloride in tablet formulations.

Validation of the method for amiodarone hydrochloride will be performed according to the requirements of USP for assay determination which include accuracy, precision, selectivity, linearity and range, while validation of the method for amiodarone impurities will be performed according to the requirements of USP for quantitative determination of impurities which include accuracy, precision, selectivity, linearity and range, and Limit of quantitation.

\section{Material and Methods}

\section{Chemicals}

Acetonitrile and methanol HPLC grade are from J.T Baker (NJ,

Corresponding author: Fuad Al-Rimawi, Faculty of Science and Technology, AlQuds University, P.O. Box 20002, East Jerusalem, E-mail: fuad 12345@yahoo. com

Received August 28, 2010; Accepted September 25, 2010 Published September 27, 2010

Citation: Al-Rimawi F (2010) Validation of an HPLC-UV Method for the Determination of Amiodarone Impurities in Tablet Formulaions. Pharm Anal Acta 1:105. doi:10.4172/2153-2435.1000105

Copyright: ( 2010 Al-Rimawi F. This is an open-access article distributed under the terms of the Creative Commons Attribution License, which permits unrestricted use, distribution, and reproduction in any medium, provided the original author and source are credited. 
USA). Glacial acetic acid and ammonia are from Merck (Darmstadt, Germany). Amiodarone hydrochloride and its impurities (D and E) are from European Pharmacopeia (Strasbourg Cedex).

\section{Apparatus}

HPLC system (Merck Hitachi Lachrome Elite HPLC system, Japan) with an L-2130 pump, an L-2200 autosampler, L-2300 column oven, and L-2490 UV detector was employed. The Ezochrom Elite software was employed. C18 column $(5 \mu \mathrm{m}, 150 \mathrm{~mm}$ length, 4.6 $\mathrm{mm}$ inner diameter) was used in this study and it is from Waters Corporation (Milford, Massachusetts, USA). The column is kept at room temperature.

\section{Standard solutions preparation}

Buffer solution was prepared by mixing $3.0 \mathrm{~mL}$ of glacial acetic acid with $1000 \mathrm{~mL}$ of water for HPLC, and adjusting the pH to 5.0 with dilute ammonia solution. Diluent was prepared by mixing equal volumes of acetonitrile and water.

Stock standard solution of amiodarone hydrochloride was prepared by dissolving $100 \mathrm{mg}$ of amiodarone hydrochloride in 100 $\mathrm{mL}$ of methanol to obtain a solution having a known concentration of $1.0 \mathrm{mg} \mathrm{mL}^{-1}$. Nominal standard solution was prepared by diluting $1 \mathrm{~mL}$ of stock standard solution to $100 \mathrm{~mL}$ with diluent to obtain a solution having a known concentration of $0.01 \mathrm{mg} \mathrm{mL}^{-1}$ amiodarone hydrochloride.

System suitability solution was prepared by dissolving $5.0 \mathrm{mg}$ of amiodarone hydrochloride, $5.0 \mathrm{mg}$ of amiodarone impurity $\mathrm{D}$, and $5.0 \mathrm{mg}$ of amiodarone impurity $\mathrm{E}$ in $25.0 \mathrm{~mL}$ of methanol and diluting $1.0 \mathrm{~mL}$ of this solution to $20.0 \mathrm{~mL}$ with diluent (concentration $=0.01$ $\mathrm{mg} \mathrm{mL} \mathrm{m}^{-1}$ of each).

Sample of formulated amiodarone hydrochloride (tablets) for the determination of amiodarone impurities was prepared by dissolving a quantity of the powdered tablet equivalent to $200 \mathrm{mg}$ of amiodarone hydrochloride in $50 \mathrm{~mL}$ of methanol, and diluting $25.0 \mathrm{~mL}$ of this solution to $50.0 \mathrm{~mL}$ with diluent $\left(1.0 \mathrm{mg} \mathrm{mL}^{-1}\right)$.

\section{Standard solutions for validation study}

Validation of the method for the determination of amiodarone hydrochloride

Linearity and range: Stock standard solution of amiodarone hydrochloride with a concentration of $0.1 \mathrm{mg} \mathrm{mL}^{-1}$ was prepared by dissolving $20.0 \mathrm{mg}$ of amiodarone hydrochloride in $200 \mathrm{~mL}$ of methanol. Five solutions of amiodarone hydrochloride with different concentrations $\left(0.005,0.0075,0.01,0.0125,0.0150 \mathrm{mg} \mathrm{mL}^{-1}\right)$ for linearity study were prepared by diluting different volumes of the stock standard solution. The following dilutions were used: $5.0 \mathrm{~mL}$ of stock standard solution was diluted to $100.0 \mathrm{~mL}$ with diluent $(0.0050$ $\left.\mathrm{mg} \mathrm{mL} \mathrm{m}^{-1}\right), 15.0 \mathrm{~mL}$ of stock standard solution was diluted to 200.0 $\mathrm{mL}$ with diluent $\left(0.0075 \mathrm{mg} \mathrm{mL}^{-1}\right), 10.0 \mathrm{~mL}$ of stock standard solution was diluted to $100.0 \mathrm{~mL}$ with diluent $\left(0.01 \mathrm{mg} \mathrm{mL}^{-1}\right), 25.0 \mathrm{~mL}$ of stock standard solution was diluted to $200.0 \mathrm{~mL}$ with diluent $(0.0125 \mathrm{mg}$ $\left.\mathrm{mL}^{-1}\right), 15.0 \mathrm{~mL}$ of stock standard solution was diluted to $100.0 \mathrm{~mL}$ with diluent $\left(0.015 \mathrm{mg} \mathrm{mL}^{-1}\right)$.

Accuracy (\% recovery): Three solutions of amiodarone hydrochloride with concentrations of $0.005,0.01$, and $0.015 \mathrm{mg}$ $\mathrm{mL}^{-1}$ were prepared by spiking amiodarone hydrochloride in the excepients (placebo) of the tablet formulation. Accordingly, 5, 10 and $15 \mathrm{~mL}$ of the stock standard solution of amiodarone hydrochloride $\left(0.1 \mathrm{mg} \mathrm{mL}^{-1}\right)$ were added to the placebo of the drug formulation, and diluting to $100 \mathrm{~mL}$ with diluent. The resulting three solutions contain $0.005,0.01$, and $0.015 \mathrm{mg} \mathrm{mL}^{-1}$ of amiodarone hydrochloride spiked in the excepients.

\section{Validation of the method for the determination of amiodarone impurities}

Linearity and range: Stock standard solution of amiodarone impurity $\mathrm{D}$ with a concentration of $1.0 \mathrm{mg} \mathrm{mL}^{-1}$ was prepared by dissolving $100.0 \mathrm{mg}$ of amiodarone impurity $\mathrm{D}$ in $100 \mathrm{~mL}$ of diluent. Six solutions of amiodarone impurity $\mathrm{D}$ were prepared for linearity study by diluting specific volumes of the stock standard solution to get several concentrations of impurity D $(0.075,0.050,0.025,0.0050$, 0.0025 , and $0.0005 \mathrm{mg} \mathrm{mL}^{-1}$ ). The following dilutions were used: 15.0 $\mathrm{mL}$ of stock standard solution was diluted to $200.0 \mathrm{~mL}$ with diluent (0.075 mg mL-1, solution 1 ), $5.0 \mathrm{~mL}$ of stock standard solution was diluted to $100.0 \mathrm{~mL}$ with diluent $\left(0.050 \mathrm{mg} \mathrm{mL}^{-1}\right.$, solution 2$), 5.0 \mathrm{~mL}$ of stock standard solution was diluted to $200.0 \mathrm{~mL}$ with diluent (0.025 $\mathrm{mg} \mathrm{mL}^{-1}$, solution 3), $10.0 \mathrm{~mL}$ of solution 2 was diluted to 100.0 $\mathrm{mL}$ with diluent $\left(0.0050 \mathrm{mg} \mathrm{mL}^{-1}\right.$, solution 4$), 5.0 \mathrm{~mL}$ of solution 2 was diluted to $100.0 \mathrm{~mL}$ with diluent $\left(0.0025 \mathrm{mg} \mathrm{mL}^{-1}\right.$, solution 5$), 10.0$ $\mathrm{mL}$ of solution 4 was diluted to $100.0 \mathrm{~mL}$ with diluent $(0.0005 \mathrm{mg}$ $\mathrm{mL}^{-1}$, solution 6).

The same procedure was repeated for amiodarone impurity $\mathrm{E}$.

Limit of detection (LOD) and limit of quantitation (LOQ): The solution of amiodarone impurity D with a concentration of $0.0005 \mathrm{mg}$ $\mathrm{mL}^{-1}$ which is prepared in the linearity section is used for this study. This solution was diluted stepwise to get several concentrations $\left(0.0004,0.0003,0.0002\right.$ and $\left.0.0001 \mathrm{mg} \mathrm{mL}^{-1}\right)$. These solutions are chromatographed and the signal to noise ratio of each concentration was determined.

The same procedure was repeated for amiodarone impurity E.

Accuracy (\% recovery): Three solutions of amiodarone impurity D with concentrations of $0.075,0.005$, and $0.0005 \mathrm{mg} \mathrm{mL}^{-1}$ were prepared by spiking this impurity with the active ingredient (amiodarone hydrochloride) at a concentration of $1.0 \mathrm{mg} \mathrm{mL}^{-1}$ and the excepients of the tablet formulation.

The same procedure was repeated for amiodarone impurity $\mathrm{E}$.

\section{Results}

\section{Method development}

C18 column ( $5 \mu \mathrm{m}, 150 \mathrm{~mm}$ length, $4.6 \mathrm{~mm}$ inner diameter) was used in this study for the separation of amiodarone hydrochloride and its two impurities (D and E), using a mixture of buffer $\mathrm{pH}$ 5.0, methanol and acetonitrile $(30: 30: 40, \mathrm{v} / \mathrm{v} / \mathrm{v})$ as a mobile phase at a flow rate of $1.0 \mathrm{~mL} \mathrm{~min}^{-1}$ and UV detection at $240 \mathrm{~nm}$ and injection volume of $10 \mu \mathrm{L}$.

Using this method, a good separation with adequate resolution was obtained for amiodarone hydrochloride and its impurities see Figure 2. Table 1 shows the chromatographic parameters of the separated peaks in Figure 2.

\section{Method validation}

Validation of the method for the determination of amiodarone hydrochloride: Method validation for the determination of amiodarone hydrochloride was performed in accordance with USP requirements for assay determination (Category-I: Analytical methods 


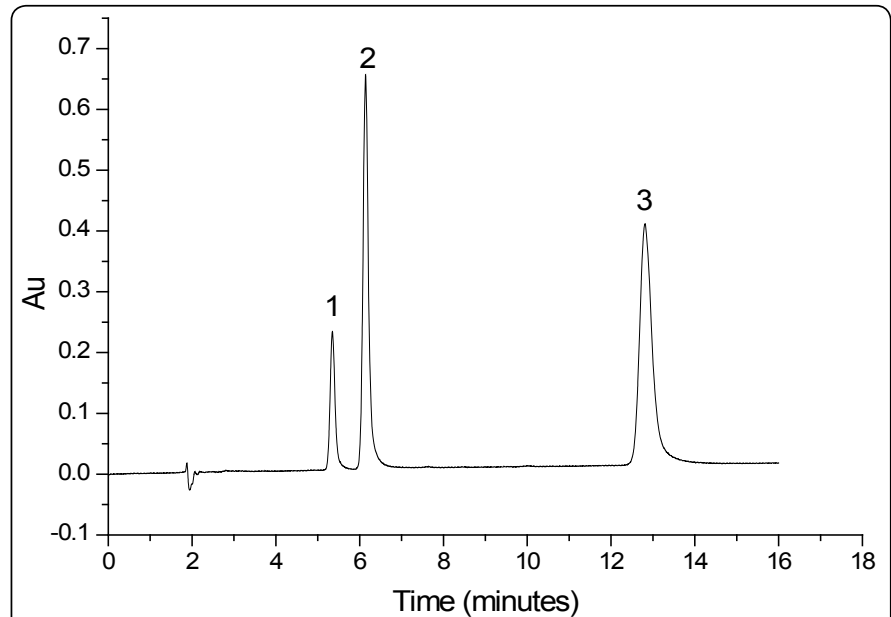

Figure 2: Chromatogram of amiodarone hydrochloride and its impurities ( $D$ and $E), 0.01 \mathrm{mg} \mathrm{mL}-1$ of each. Mobile phase: buffer $\mathrm{pH} 5.0$, methanol acetonitrile $(30: 30: 40, \mathrm{v} / \mathrm{v} / \mathrm{v})$, flow rate $1.0 \mathrm{~mL}$ min-1, injection volume $10 \mu \mathrm{L}$. Column: C18 (5 $\mu \mathrm{m}, 150 \mathrm{~mm}$ length, $4.6 \mathrm{~mm}$ inner diameter), UV detection $240 \mathrm{~nm}$. Peaks identification: (1) amiodarone impurity D (2): amiodarone impurity $\mathrm{E}(3)$ : amiodarone hydrochloride.

\begin{tabular}{|l|l|l|l|l|}
\hline Analyte & $\begin{array}{l}\text { Theoretical } \\
\text { plates }\end{array}$ & Asymmetry & Resolution & $\begin{array}{l}\text { Relative } \\
\text { retention } \\
\text { time }\end{array}$ \\
\hline $\begin{array}{l}\text { Amiodarone } \\
\text { impurity D }\end{array}$ & 10600 & 1.22 & 3.6 & 0.44 \\
\hline $\begin{array}{l}\text { Amiodarone } \\
\text { impurity E }\end{array}$ & 11500 & 1.29 & 17.0 & 0.50 \\
\hline $\begin{array}{l}\text { Amiodarone } \\
\text { hydrochloride }\end{array}$ & 9400 & 1.38 & $/$ & 1.0 \\
\hline
\end{tabular}

Table 1: Chromatographic parameters of the separated peaks in Figure 1.

for quantitation of active ingredients in finished pharmaceutical products) which include accuracy, precision, selectivity, linearity and range.

Linearity and range: To evaluate the linearity of this method, standard solutions covering the range between $50-150 \%$ of the nominal standard concentration $\left(0.01 \mathrm{mg} \mathrm{mL}^{-1}\right)$ were prepared by diluting specific volume of the stock standard to get several concentrations $\left(0.005,0.0075,0.01,0.0125,0.0150 \mathrm{mg} \mathrm{mL}^{-1}\right)$. The linearity between peak area and the concentration was examined. Results have shown that the method is linear over the specified range with $\mathrm{R}^{2}$ of 0.9994 .

Accuracy (\% recovery): Accuracy of the method was studied by spiking amiodarone hydrochloride in the placebo (excepients) of the tablet formulation. To this end, a known quantity of amiodarone hydrochloride was added to the placebo to get three concentrations $\left(0.005,0.01\right.$ and $\left.0.015 \mathrm{mg} \mathrm{mL}^{-1}\right)$. These 3 solutions are then chromatographed and the peak area resulting are compared with that of the standard to calculate the \% recovery. Results have shown that the mean recovery of amiodarone hydrochloride is within $100 \pm 2.0 \%$ for the three concentration levels. Specifically the mean recovery was found to be $99.8 \%$ for $0.005 \mathrm{mg} \mathrm{mL}^{-1}, 101.0 \%$ for $0.01 \mathrm{mg} \mathrm{mL}^{-1}$ and $98.4 \%$ for $0.015 \mathrm{mg} \mathrm{mL}^{-1}$ ).

Precision: Injection precision of this method was evaluated by calculating the RSD of the peak areas of six replicate injections of the nominal standard solution of amiodarone hydrochloride $(0.01 \mathrm{mg}$ $\mathrm{mL}^{-1}$ ), which was found to be $0.3 \%$. Furthermore, the repeatability of the method was evaluated by calculating the RSD of the peak areas of six samples of the drug tablets at the nominal concentration of amiodarone hydrochloride $\left(0.01 \mathrm{mg} \mathrm{mL}^{-1}\right)$ which was found to be $0.8 \%$.

Selectivity (stability indicating evaluation): Selectivity of the current method was demonstrated by good separation of amiodarone hydrochloride from its impurities ( $\mathrm{D}$ and $\mathrm{E}$ ) with adequate resolution, see Figure 2 and Table 1. Also, matrix components e.g. excepients do not interfere with the peaks of amiodarone hydrochloride or its impurities.

Validation of the method for the determination of amiodarone impurity D and amiodarone impurity E: Validation of the method for the determination of amiodarone impurity $\mathrm{D}$ and amiodarone impurity E was performed according to USP requirements for quantitative determination of impurities (Category II) which include accuracy, precision, selectivity, linearity and range, and LOQ.

Linearity and range: According to the ICH guidelines [5], Linearity of a method for an impurity determination should be linear from $50 \%$ of the ICH reporting limit of an impurity to $150 \%$ of the shelf life specification of that impurity. This range is to guarantee that the method for the quantitation of an impurity is linear from low concentration (e.g. $50 \%$ of the $\mathrm{ICH}$ reporting limit) to higher concentrations (e.g. $150 \%$ of the shelf life specification). According to the ICH guidelines [6], the reporting limit of an impurity is $0.1 \%$ when the maximum daily dose of a drug substance is $\leq 1 \mathrm{~g}$, as in the case of amiodarone hydrochloride. Regarding shelf life specification of an impurity, it depends on the impurity itself and its toxicity. So taking $0.1 \%$ as the ICH reporting limit and $5 \%$ as the shelf life specification for amiodarone impurity $\mathrm{D}$ and amiodarone impurity $\mathrm{E}$, the current method has to be linear from $0.05 \%-7.5 \%$ of the concentration of amiodarone hydrochloride. For the determination of impurities, it is recommended that the concentration of amiodarone hydrochloride is high so that impurities (which are present in low concentrations) can be detected and quantitated. Accordingly, the concentration of amiodarone hydrochloride in the sample of amiodarone hydrochloride tablets used for quantitation of impurities is $1.0 \mathrm{mg} \mathrm{mL}^{-1}$. Therefore linearity of the current method for the determination of amiodarone impurity D and impurity $\mathrm{E}$ has to be studied from $0.05 \%-7.5 \%$ of the concentration of amiodarone hydrochloride $\left(1.0 \mathrm{mg} \mathrm{mL}^{-1}\right)$ which corresponds to $0.0005-0.075 \mathrm{mg} \mathrm{mL}^{-1}$ of amiodarone impurity $\mathrm{D}$ and impurity E. Accordingly six concentrations of amiodarone impurity D $\left(0.075,0.050,0.025,0.0050,0.0025\right.$ and $0.0005 \mathrm{mg} \mathrm{mL}^{-}$ $\left.{ }^{1}\right)$ and six concentrations of amiodarone impurity $\mathrm{E}(0.075,0.050$, $0.025,0.0050,0.0025$ and $0.0005 \mathrm{mg} \mathrm{mL}^{-1}$ ) were prepared and chromatographed, and the peak areas resulted were recorded and plotted versus concentration. Results have shown that this method is linear for the determination of amiodarone impurity $D$ (with $R^{2}$ of 0.9990) and impurity $E$ (with $R^{2}$ of 0.9992). Another parameter which is used to evaluate the linearity of this method is the $y$-intercept to slope ratio which has a unit of impurity concentration (in $\mathrm{mg} \mathrm{mL}^{-1}$ ) and should be very low (not significant). This ratio was found to be $0.00005 \mathrm{mg} \mathrm{mL}^{-1}$ for amiodarone impurity $\mathrm{D}$ and $0.00003 \mathrm{mg} \mathrm{mL}^{-1}$ for amiodarone impurity $\mathrm{E}$. These values are very low compared to the shelf life specification of these impurities (e.g. $1 \%$ of the concentration of amiodarone hydrochloride which is equivalent to $0.01 \mathrm{mg} \mathrm{mL}^{-1}$ ) and it represents only about $0.5 \%$ of this specification.

Limit of detection (LOD) and limit of quantitation (LOQ): According to ICH guidelines [5], LOQ of an impurity should be less than the ICH reporting limit of this impurity (e.g. $50 \%$ of this limit). This limit is set to ensure that the impurity at this low concentration can be quantitated. For amiodarone imp urities (D and E), the reporting limit 


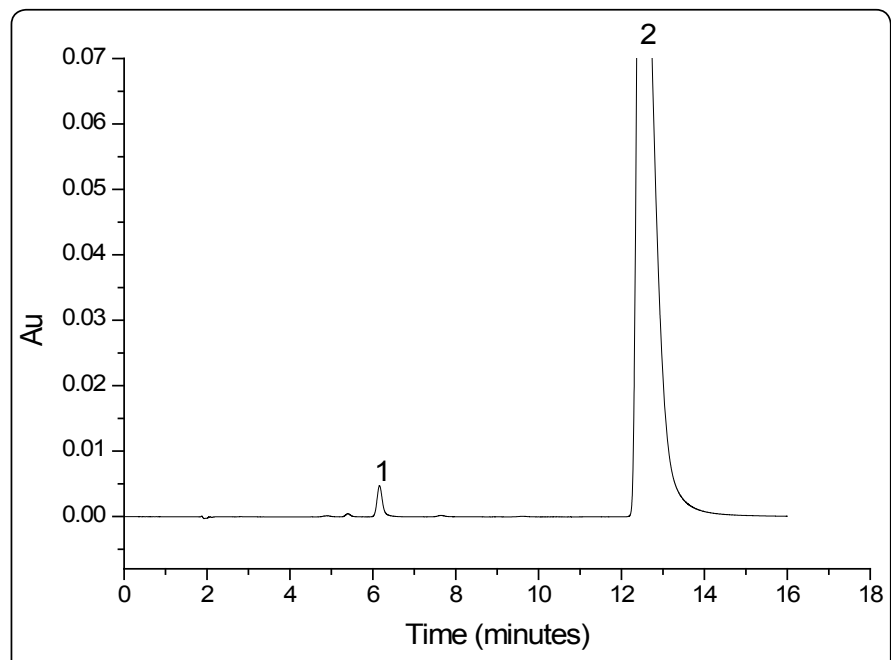

Figure 3: Chromatogram of amiodarone impurity $\mathrm{D}\left(0.0005 \mathrm{mg} \mathrm{mL}^{-1}\right)(1)$ and amiodarone hydrochloride $\left(1.0 \mathrm{mg} \mathrm{mL}^{-1}\right)(2)$. For other experimental conditions, see Figure 2.

is $0.1 \%$, so the LOQ has to be less than this limit (e.g. 0.05\%). LOQ for amiodarone impurity $\mathrm{D}$ was determined by preparing a solution at a concentration of $0.0005 \mathrm{mg} \mathrm{mL}^{-1}$ (50\% of the ICH reporting limit) and diluting this solution stepwise and analyzing these solutions and calculating the signal to noise ratio for each concentration. LOQ is selected to be the concentration that gives a signal to noise ratio of 10-20. In the same manner, LOD was determined where it is selected to be the concentration that gives a signal to noise ratio of 3-10. The same procedure was repeated for amiodarone impurity $\mathrm{E}$.

Results have shown that the LOD and LOQ for impurity D are $0.0002 \mathrm{mg} \mathrm{mL}^{-1}$ and $0.0004 \mathrm{mg} \mathrm{mL}^{-1}$, respectively. It was also found that LOD and LOQ for amiodarone impurity E are $0.0001 \mathrm{mg} \mathrm{mL}^{-1}$ and $0.0004 \mathrm{mg} \mathrm{mL}^{-1}$, respectively.

Accuracy (\% recovery): According to ICH guidelines [5], accuracy of a method for the determination of impurities is assessed on samples of drug product spiked with known amounts of impurities at three concentration levels of impurities. Accordingly, amiodarone impurities were spiked in the excepients of tablet formulation and the active ingredient (amiodarone hydrochloride) to get three concentration levels of amiodarone impurities (see the experimental part). These three solutions are then chromatographed and the peak areas are recorded and compared with standards of amiodarome impurity D. It was found that the average recovery of amiodarone impurity D for the three levels is $103.5 \%$ with a relative standard deviation of $1.76 \%$. The chromatogram (Figure 3$)$ of amiodarone impurity D $(0.0005 \mathrm{mg}$ $\left.\mathrm{mL}^{-1}\right)$ and amiodarone hydrochloride $\left(1.0 \mathrm{mg} \mathrm{mL}^{-1}\right)$ shows that this impurity can be recovered at this low concentration.

The same procedure was repeated for amiodarone impurity E, and results showed that the average recovery of amiodarone impurity E for the three levels is $99.6 \%$ with a relative standard deviation of $1.30 \%$.
Precision: Injection precision of this method was evaluated by calculating the RSD of the peak areas of six replicate injections of the solution of amiodarone impurity $\mathrm{D}$ at a concentration of $0.0005 \mathrm{mg}$ $\mathrm{mL}^{-1}$, which was found to be $0.9 \%$. Furthermore, the repeatability of the method was evaluated by calculating the RSD of the peak areas of six samples of amiodarone impurity $D$ at a concentration of $0.0005 \mathrm{mg}$ $\mathrm{mL}^{-1}$ and amiodarone hydrochloride at a concentration of $1.0 \mathrm{mg} \mathrm{mL}^{-1}$ (i.e the accuracy solution which is used in accuracy study) which was found to be $1.3 \%$.

The same procedure was repeated for amiodarone impurity $\mathrm{E}$ and results showd that the RSD (which reflects the injection precision) of the peak areas of six replicate injections of the solution of amiodarone impurity $\mathrm{E}$ at a concentration of $0.0005 \mathrm{mg} \mathrm{mL}^{-1}$ is $0.82 \%$. Furthermore, the repeatability of the method was evaluated by calculating the RSD of the peak areas of six samples of amiodarone impurity $E$ at a concentration of $0.0005 \mathrm{mg} \mathrm{mL}^{-1}$ and amiodarone hydrochloride at a concentration of $1.0 \mathrm{mg} \mathrm{mL}^{-1}$ (i.e the accuracy solution which is used in accuracy study) which was found to be $1.78 \%$.

Selectivity: Selectivity of the current method for the separation of amiodarone impurities was demonstrated by separation of amiodarone impurities ( $D$ and $E$ ) from each other and from amiodarone hydrochloride with adequate resolution; see Figure 2 and Table 1. Also, matrix components e.g. excepients do not interfere with the peaks of amiodarone hydrochloride or its impurities.

\section{Conclusion}

A simple, accurate and precise stability-indicating HPLC method is presented for the analysis of amiodarone hydrochloride and its impurities ( $D$ and $E$ ) in tablet formulations. The method is valid for the determination of amiodarone hydrochloride as well as its impurities (D and E). Low LOD and LOQ of the two impurities using this method enable the detection and quantitation of these impurities at low concentration.

\section{Acknowledgments}

I would like to thank gratefully Birzeit Pharmaceuticals for their support and providing the necessary instruments/apparatus to perform this study.

\section{References}

1. Lacroix PM, Curran NM, Wing-Wah SY, Gorecki DKJ, Thibault P, et al. (1994) Liquid chromatographic determination of amiodarone hydrochloride and related compounds in raw materials and tablets. J AOAC Int 77: 1447-1453.

2. Thyagarajapuram N, Alexander KS (2003) A simplified method for the estimation of amiodarone hydrochloride by reverse-phase high performance liquid chromatography. J Liq Chrom \& Rel Technol 26: 1315-1326.

3. Christopherson MJ, Yoder KJ, Miller RB (2004) Validation of a stabilityindicating HPLC method for the determination of amiodarone $\mathrm{HCl}$ and its related substances in amiodarone $\mathrm{HCl}$ injection. J Liq Chrom \& Rel Technol 27: 95-111.

4. Khan MA, Kumar S, Jayachandran J, Vartak SV, Bhartiya A, et al. (2005) Validation of a stability indicating LC method for amiodarone $\mathrm{HCl}$ and related substances. Chromatographia 61: 599-607.

5. ICH Harmonised Tripartite Guideline (1994) Validation of analytical procedures: Text and methodology Q2 (R1).

6. ICH Harmonised Tripartite Guideline (2006) Impurities in new drug products Q3B (R2). 